\title{
PATRIMÔNIO CULTURAL RELIGIOSO NA CIDADE DE JUAZEIRO DO NORTE - CEARÁ - BRASIL E A TESE DE TOMBAMENTO AFETIVO EM GEOGRAFIA
}

\author{
CULTURAL AND RELIGIOUS HERITAGE IN THE CITY OF JUAZEIRO DO NORTE - CEARA AND THE AFFECTIVE HERITAGE \\ PROTECTION THESIS IN GEOGRAPHY
}

\section{RESUMO}

Interessa-nos apresentar neste artigo a formulação de uma tese envolvendo tombamento afetivo em geografia. A tese está fundamentada no estudo de dois patrimônios religiosos urbanos diferenciados ocupando um mesmo espaço no centro da cidade de Juazeiro do Norte no estado do Ceará. O primeiro trata-se do conjunto patrimonial Praça do Largo do Socorro. O segundo, idealizado como atrativo turístico, foi implantado nesta mesma praça como espaço museal e memorial. A análise destaca particularmente as diferenças conceituais entre estes dois patrimônios e, nos termos desta análise, apresentamos a tese de tombamento afetivo patrimonial. Propomos discutir a tese de que a Praça do Largo do Socorro é tombada por meio da afetividade humana, pois trata-se de um espaço de forte dinâmica simbólica assentada na religiosidade popular a qual se transformou em herança patrimonial através das vivências e das dinâmicas simbólicas envoltas ao religioso.

Palavras-chave: Largo do Socorro; Afetividade humana; Sentimentos; Tombamento afetivo; Juazeiro do Norte.

\section{ABSTRACT}

We present in this article the formulation of a thesis involving geography, affectivity and heritage. The thesis is based on the study of two distinct urban religious sites occupying the same space in downtown Juazeiro do Norte city, in the state of Ceara - Brazil. The first is the heritage complex Largo do Socorro Square. The second one, idealized as a tourist attraction, was implanted in the same square as a museum and memorial space. The analysis highlights particularly the conceptual difference between these two heritages and, in terms of these analysis, we present the thesis of affective protection heritage. We propose to discuss the thesis that Largo do Socorro Square is protected through human affectivity, since it is a space of strong symbolic dynamics based on popular religiosity. This square became an affective and social heritage through its strong social and cultural symbolism of religiosity.

Keywords: Largo do Socorro; Human affectivity; Feelings; Affective heritage; Juazeiro do Norte.

\author{
Raimundo Freitas Aragão a \\ Tiago Vieira Cavalcante ${ }^{a}$ \\ a Universidade Federal do Ceará (UFC), \\ Fortaleza, CE, Brasil
}

DOI: $10.12957 /$ geouerj.2020.43612

Correpondência:

tiagogeografiaufc@gmail.com

Recebido em: 20 jun. 2019

Aceito em: 27 mai.2020 


\section{INTRODUÇÃO}

O Largo do Socorro é um complexo patrimonial formado por igreja, cemitério, monumentos, memorial e museu. Localizado no centro da cidade de Juazeiro do Norte, lugar de forte dinâmica simbólica cuja representação maior na paisagem é a figura do santo popular Cícero Romão Batista. Nestes termos, temos como objetivo fornecer uma análise deste espaço urbano público patrimonial ímpar, cuja intervenção está consolidada na cultura religiosa popular, em suas romarias e na afetividade prolongada de moradores e visitantes, contrapondo-o ao Memorial Padre Cícero construído em sua área de domínio e associado à afetividade de tempo curto.

O recurso metodológico utilizado foi a pesquisa qualitativa. As técnicas, além do levantamento bibliográfico, foi o de observação participante, considerada importante e essencial quando se trata do campo religioso, dado a inserção do pesquisador nas práticas culturais mais íntimas e vivenciais do lugar. Participamos durante três anos de quatro das principais romarias. Os resultados finais desta investigação demonstram que o Largo do Socorro passa por processo perene de construção patrimonial de base social e que tal complexo é incessantemente tombado por meio da afetividade, isto é, da relação íntima, próxima, que as pessoas constroem cotidianamente com esse lugar.

Utilizamos a Geografia Cultural, pois esta nos possibilita observar como as ideologias e os ideários humanos são desenvolvidos na sociedade, isso levando em conta que ela tem como objetivo "[...] entender a experiência dos homens no meio ambiente e social, compreender a significação que estes impõem ao meio ambiente e o sentido dado às suas vidas" (CLAVAL, 2002, p. 20), pois a mesma integra tanto as representações mentais quanto as reações subjetivas. No nosso caso, o contexto religioso, suas práticas culturais e sua inserção na paisagem humana concreta, a partir de seus símbolos, e abstrata, por meio dos simbolismos.

Como aliada à Geografia Cultural, partilhamos a Geografia Social ou relacional, pelo fato destas se inscreverem nas relações socioespaciais, privilegiando os atores os quais constroem suas interpretações sobre o espaço, levando-os a elaborar seus sistemas territoriais no trajeto relação sujeito-objeto (DI MEO, 1996; MONNET, 2011). Trazemos, da mesma forma, a colaboração das geografias humanista e fenomenológica existencial. Ambas centralizam o ser humano nas bases de sua complexidade subjetiva e existencial, pois buscam o ser humano como principal caminho das análises geográficas (HOYAUX, 2000, DARDEL, 2011), ou melhor, propõem entender o ser-no-mundo e a construção do seu lugar, do seu território. $\mathrm{O}$ artigo terá da mesma forma, auxílio de outras disciplinas próximas no entendimento de conceitos os quais não são familiares à geografia, como os de afetividade, afeto, emoção e sentimento. Partimos dessa referência por acreditarmos que ela poderá contribuir para que religião, afetividade e patrimônio possam cooperar com a tese formulada. 
O artigo está dividido em cinco partes. A primeira é esta introdução. A segunda traz a discussão sobre o significado de afetividade humana como arcabouço de compreensão da tese do tombamento afetivo em geografia. A terceira parte traz o exemplo do Memorial Padre Cícero como exemplo de "lugar de patrimonialização", com a finalidade de contrapô-lo em termos afetivos ao Largo do Socorro. A quarta apresenta o Largo do Socorro como "lugar de patrimônio"; é o exemplo empírico de apresentação da tese do tombamento afetivo. Na quinta parte, enfim, estão considerações gerais onde o enfoque são as reflexões sobre o apanhado geral da pesquisa.

\section{Apanhado conceitual para uma tese de tombamento afetivo em Geografia}

O "Novo Dicionário da Língua Portuguesa" conceitua afeto como sinônimo de afeição, simpatia, amizade, amor, sentimento, paixão. No entanto, quando o dicionário busca na psicologia a definição de afetividade, lança: "conjunto de fenômenos psíquicos que se manifestam sob a forma de emoções, sentimentos e paixões, acompanhados sempre da impressão de dor ou prazer, da satisfação ou insatisfação, do agrado ou desagrado, da alegria ou da tristeza" (HOLANDA, 1986, p. 55).

A geógrafa Claire Damery (2008) destaca detalhe interessante relacionado à questão semântica entre os termos "afeto" e "afetividade". Ela discorre sobre a noção geral de afeto como mecanismo psicológico ligado ao tempo curto, ou seja, à experiência ou reação em que existe um tempo efêmero mais imediato; o afeto, portanto, está ligado à sua tipologia emoção. Já a afetividade engloba contextos mais gerais como "emoções" e também "sentimentos", este último tipo essencial para nós.

Assim, emoções e sentimentos são tipos de afetos e se diferenciam pelas suas durações. As emoções estão situadas no nível fisiológico (de sensação física) e psicológico (subjetivo) causadas por estímulos internos e por estímulos externos com consequências concretas ou intangíveis sobre o espaço social. Este tipo de afeto é efêmero, porém acompanhado de significativo grau de intensidade. Para o neurologista Antônio Damásio (2004), as emoções têm caráter físico (neurobiológico) e são reações que o corpo sofre a certos estímulos, surgindo automática e inconscientemente. Ele exemplifica o medo, emoção provocadora de reações não controladas por parte de quem o sofre. A pessoa, ao sentir medo, neste caso dependendo de sua intensidade, espontaneamente acelera seu ritmo cardíaco, seca a boca, os seus músculos se contraem etc. No que se refere à duração das emoções, não se pode sentir o medo por horas, ele é instantâneo, daí a condição de efemeridade das emoções.

Ao contrário, os sentimentos são estados afetivos duráveis e estão escondidos no íntimo pessoal, surgindo quando tomamos consciência das "emoções" corporais sob a forma de uma atividade neuronal (DAMÁSIO, 2004). Assim, podemos dizer que os sentimentos partem das emoções, quando seus componentes 
cognitivos são ativados. Enquanto as emoções são perceptíveis e partilháveis, os sentimentos são privativos de cada sujeito, possuidores de um mapa pessoal de sentimentos. Porém, nem todo sentimento surge da reação corporal, ele pode ser recuperado do interior da pessoa quando esta se faz recordar, por exemplo, de um momento agradável, entretanto o sentimento só será intenso quando o próprio corpo participar do ocorrido.

As considerações de Damásio são de extrema importância, porém, Damery (2008) considera os apanhados conceituais advindos da neurologia, psicanálise ou da psiquiatria insuficientes para explicar o afeto em suas dimensões sociais e culturais, pois estas ciências restringem o emprego do afeto à experiência interior. É preciso ir além e levar o afeto compreendido à luz das ciências sociais e humanas, pelo motivo de tais ciências comporem seu arcabouço teórico centralizando-o nas dimensões coletivas da experiência. Além do afeto psicológico, neurológico, a Geografia Afetiva da Experiência do Espaço por ela trabalhada recorre aos postulados epistemológicos destas outras ciências.

Para Damery (2008), os afetos possuem dimensões. Primeiro eles são produtores de significados justamente quando são conduzidos às esferas do social e do cultural, tanto no sentido individual quanto no coletivo, pois é na esfera do social e do cultural onde se encontra a dimensão existencial. Esta dimensão permite aos indivíduos se reposicionarem em relação a seus valores. Neste contexto, são nesses valores que a autora busca respaldo teórico para sua concepção de "dimensão afetiva da experiência" trazendo para seu campo de análise teóricos da fenomenologia, das ciências cognitivas e do existencialismo e mostrando de que forma estudiosos de outras áreas como a antropologia, a psicologia e até mesmo politólogos, estão de acordo que o afeto e suas tipologias, emoções e sentimentos participam de um sistema de sentidos e de valores de um grupo social, construindo, dessa forma, um laço entre eles. É preciso aqui trazer na íntegra a conclusão do que ela considera essa primeira dimensão do afeto, a "dimensão da experiência".

[...] a dimensão afetiva da experiência seria ao mesmo tempo um meio pelo qual o indivíduo constrói a experiência dos valores, e uma expressão significativa de sua relação ao mundo. Parece que, em primeiro lugar, os afetos podem ser convocados como julgamentos de valores apropriados a certas situações. O lugar de sepulturas, quando se trata de nossa cultura ocidental, em mostrar compaixão e tristeza, é um bom exemplo. Esta expressão afetiva testemunha de uma forma o respeito pela família em luto, como aos próprios mortos. Os afetos conduzem então características morais em relação ao ambiente. A manifestação de tal emoção atesta o sentido do ambiente ligado ao contexto e ao sítio. Em segundo lugar, a dimensão afetiva da experiência do indivíduo pode entrar em ressonância com "um evento passado, presente ou futuro, real ou imaginário" que revela a relação do indivíduo ao mundo, e seus próprios valores para a apreensão deste mundo. Assim, os afetos permitem ao sujeito de reavaliar sem cessar sua própria consciência emocional de um evento, em relação a valores herdados do grupo sociocultural no qual está inscrito, e inversamente (DAMERY, 2008, p. 273).

Isto nos mostra a relação da experiência afetiva do homem com o ambiente que o que o envolve, com seu lar, com seu habitar, na mais íntima presença com o lugar, ou mais, do ser-no-mundo, pois o "[...] costume de dar à tumba ou à urna funerária a forma de casa, o desejo manifestado até nossa época, pelos povos mais 
diversos, [...] deriva dessa relação afetiva do homem com a Terra" (DARDEL, 2011, p. 49). Manifestação construída pelo entendimento mítico de que "[...] toda sepultura vem desmentir a morte por que ela proclama a consanguinidade imortal daqueles que nela descansa. Ela certifica contra a morte das civilizações, da imortalidade das dinastias [...]" (DURANT, 1994, p. 20).

A segunda dimensão emana da primeira, neste caso, os afetos testemunham processos de identidade e de sociabilidade de uma pessoa ou grupo e são exercidos através do que ela chama de "laços obrigatórios", isto é, da comunicação social ritualmente organizada. Com isso, a "[...] dimensão afetiva da experiência deverá então ser encarada como expressão identitária do indivíduo" (DAMERY, 2008, p. 273); uma segunda dimensão que não pode estar ausente e desassociada da primeira e, reciprocamente, se completam. Como os sujeitos não vivem isolados, os afetos constituem potentes ferramentas de construção de laços sociais, a terceira forma de expressão da dimensão afetiva da experiência. Assim, os afetos são importantes nas relações de encontros de sociabilidade, pois é a partir desses encontros que se produzem as dinâmicas de comunicação ou mesmo de transmissão.

A partir desta problemática, envolvendo a semântica do afeto e da afetividade em torno da efemeridade das emoções e da durabilidade dos sentimentos, colocaremos em prática as duas tipologias do afeto sobre a questão patrimonial em Juazeiro do Norte. O espaço onde estão assentados o Memorial Padre Cícero e o conjunto patrimonial religioso do Largo do Socorro, no centro da cidade, comportam estas tipologias do afetivo: o de tempo curto referente ao institucional e o de tempo longo do patrimônio coletivo e referente ao tombamento afetivo, tanto do ambiente imaterial simbólico quanto do objeto construído.

Concordamos mais uma vez com Damery (2008, p. 281) quando esta reforça a hipótese geral de sua tese afirmando que "[...] as formas geográficas fortemente simbólicas são condutoras de 'meios afetivos' duráveis, propícios ao desenrolar do acontecimento público". É o pântano a ser cruzado de um lado a outro, ele pode parecer perigoso, porém os patrimônios poderão ser nossa travessia segura, é o que gostaríamos de mostrar, a partir de agora, com os exemplos destas formas patrimoniais.

Memorial Padre Cícero: um patrimônio institucional de afetividade de duração curta

O "lugar de patrimonialização" leva-nos ao conceito de patrimônio institucional. É o patrimônio controlado por instâncias cujas intervenções dependem de leis específicas baseadas em legados jurídicos colocados nas mãos de especialistas e técnicos os quais detém o poder de legitimá-lo. É o lugar onde as políticas de proteção intervêm quando as memórias lhes parecem estar à porta do arrefecimento a fim de serem realocadas na durabilidade do espaço e do tempo racionalizado. O patrimônio institucional é 
constituído através de operações de regulamentação oficial político/cultural. É o patrimônio dito "por designação".

O conjunto do acervo e o próprio Memorial Padre Cícero são salvaguardados como patrimônio institucional museal transformados, neste sentido, em "lugar de patrimonialização", pois todo o conteúdo museográfico do Memorial foi ajuntado, separado, catalogado, para servir de peças de coleção da memória de padre Cícero e de ferramenta pedagógica aos visitantes e moradores de Juazeiro do Norte. O próprio prédio é objeto catalogado como propriedade municipal. Cada peça se vê investida como memória passada, e as peças estão expostas necessariamente para não desaparecerem da história.

O Memorial, inaugurado em 22 de julho de 1988 (Figura 1), foi uma iniciativa institucional municipal de intervenção em espaço dinâmico essencialmente simbólico - O Largo do Socorro - e essa instituição exerce ainda sobre ela, controle administrativo. O Memorial é uma marcação espacial política por excelência, significa a assinatura no espaço de um grupo desejoso de instalar ali seus ideários simbólicos, políticos e elitistas, mesmo quando o discurso tenta mostrar a instalação do Memorial partindo da vontade de forças reivindicatórias sociais ordinárias. Essa "[...] tendência coletiva para a museografia une os poderes políticos que decidem construir cada vez mais museus para consagrar sua imagem a grupos sociais que são motivados, ao que parece, pelo papel que tem o museu no reconhecimento de uma identidade" (JEUDY, 1990, p. 15). Se Jeudy (2005) considera a construção de mausoléus espécies de museus para "gestão do morto", ponderamos da mesma forma, que o conteúdo patrimonial do Memorial Padre Cícero oferece aos moradores e visitantes da cidade uma "pedagogia do morto".

Figura 1. Memorial Padre Cícero. Foto: Autor, 2016.

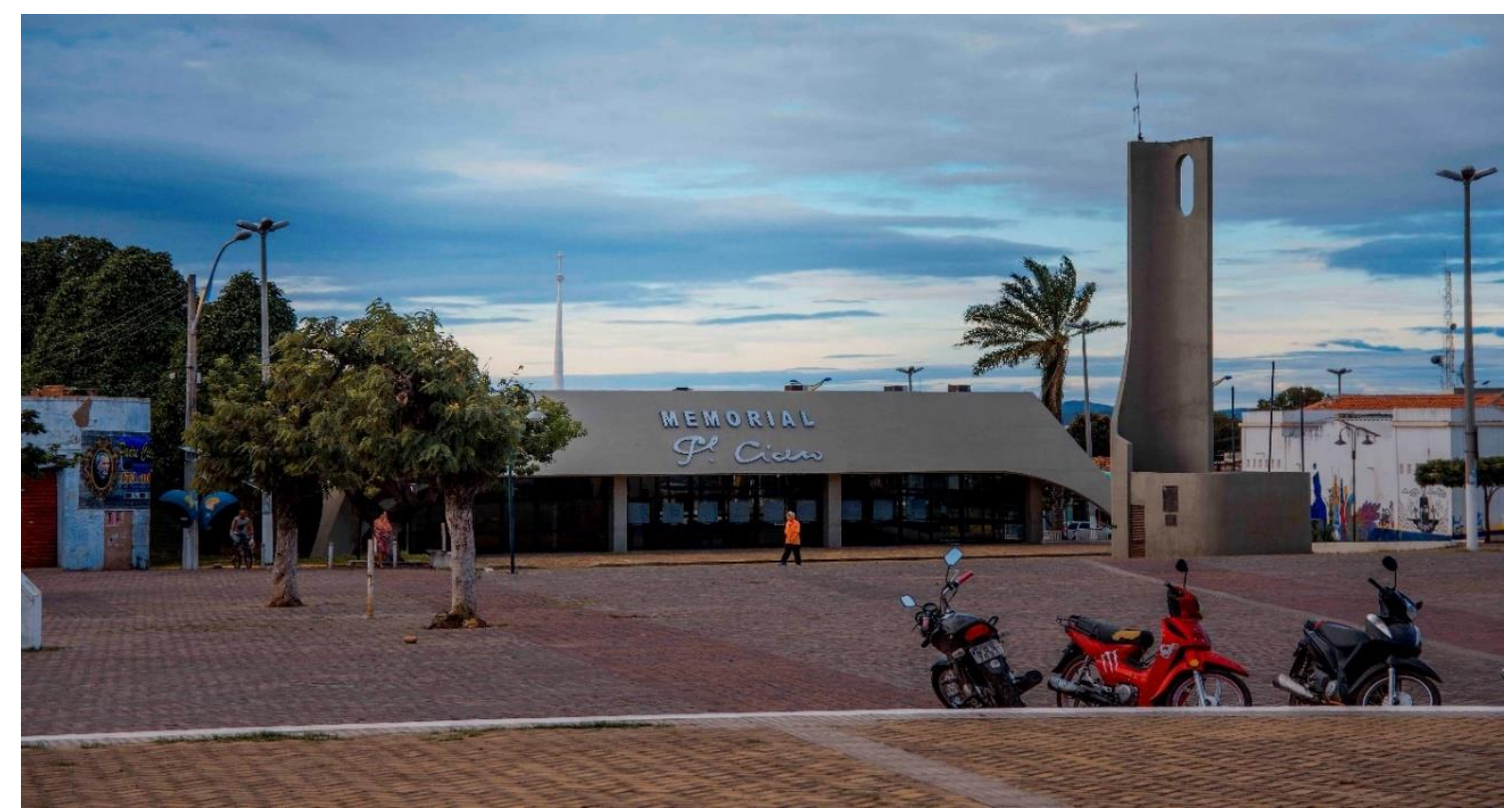


O Memorial foi construído dentro dos planos e projetos institucionais envolvidos no desenvolvimento da cultura e do turismo organizados (JUAZEIRO, 2000). O turismo e a cultura organizados e direcionados ao museu como atrativo, neste sentido, põem os objetos salvaguardados no Memorial em "[...] um lugar no conjunto ordenado por dispositivos culturais e uma legitimidade renovada pela frequentação do público" (RAUTENBERG, 2007, p. 5).

Assim, o Memorial foi idealizado para ser uma paisagem diferente e inédita no local e seu conteúdo capturado para aqueles interessados em conhecer parte da história de um homem, não a de conhecer a vida do homem ainda "vivo". O memorial é uma marcação do presente, mas que em grande parte, se alimenta da paisagem do passado, onde se vive mais os objetos como souvenires petrificados do que a representação da humanidade daquele que os possuiu. Rautenberg (2004) considera que a memória é construída no curso presente das mudanças e, no momento em que essa memória é petrificada, ela deixa de ser memória.

A construção do Memorial indica o início da salvaguarda museal de transmissão da memória do padre Cícero para o turismo, um suporte memorial material identitário. O Memorial, aproximando-se do pensamento de Jeudy (2005, p. 64), neste caso, pode ser relacionado ao que ele chama de "controle político do memorável", a "gestão do morto", ou em acepção similar, a "funcionalização do morto" (POULOT, 2009), no sentido de que esse controle ou gestão é baseado na conservação do sentido da história, para fazer com que, à medida que o tempo passe, ele possa ser capaz de trazer consolo e aceitação pública.

A inauguração do Memorial conduziu a uma estratégia ideológica de concentração e de localização espacial fechada da memória do padre Cícero. Deste modo, o modelo patrimonial do Memorial requer uma nova forma pedagógica de lidar com os objetos ali expostos, considerados relíquias, exercendo todo um controle temporal, com o estabelecimento de horários específicos e dias de visita, além de controle ostensivo e intensivo sobre seus visitantes.

No que se refere à questão da autenticidade dos objetos estudada por Berque (2007), faz-se aqui uma relação aos objetos museificados e racionalizados ao Memorial. Para ele, a autenticidade do objeto se diferencia do objeto moderno, pois a autenticidade das coisas também é a nossa, a existência humana está impregnada na existência das coisas, ela está presente em todos os poros de nosso corpo. E isto se aplica aos lugares, mas àqueles que jamais se deixam se reduzir a uma coleção de objetos.

No trato do Memorial como resgate de uma memória pessoal ou mesmo como elaboração de uma memória como identidade regional a ser patrimonializada na forma institucional é preciso observar a sintonia de dialogicidade entre os pensamentos de Oliveira (2010) e de Jeudy (1990) sobre o universo hegemônico do patrimônio e seu caráter antagônico no que concerne ao patrimônio em sua real finalidade. Para o sociólogo: “[...] a formulação de um patrimônio, sua gênese, sua atualização parte do mesmo princípio: a salvaguarda 
[ou tombamento], pura e simples, não basta, ela deve ser estimulada por um interesse coletivo de apropriação e de reconhecimento" (JEUDY, 1990, p. 8). O patrimônio não deveria ser uma aquisição e sim uma conquista social formulada pela apropriação, pois, dessa forma, ele, o patrimônio, desafiaria a regularidade do monumento histórico ou da peça museográfica. Enquanto o geógrafo centraliza a função didática, o que leva ao uso social patrimonial:

\footnotetext{
Não basta afirmar a importância e valor patrimonial de um equipamento com "resgate" das tradições expressivas de uma "verdadeira alma de um povo". O povo verdadeiro corresponde à coletividade: um espaço pulsante de múltiplos interesses. Para essa coletividade, tão complexa e diversificada, só é possível conceber um valor patrimonial legítimo - portanto mais do que legal - quando tal valor traduz um uso-didático pragmático (OLIVEIRA, 2010, p. 37).
}

Sabemos de antemão que o patrimônio social tem como característica elementar ou principal o valor de uso, valor o qual o dota de uma potência não efêmera, pois este uso-didático pragmático é dialógico, constante, integral e transformador. Em forma enfática, Oliveira (2010) afirma que é preciso conservar, sem, porém, retirar-Ihe o uso, característica intrínseca da forma social; sejam para aqueles patrimônios culturais ou naturais. O vínculo conservação-utilização é primordial porquanto é através de sua interação que se simboliza o patrimônio, em outra palavra: o ritualiza.

Estes raciocínios nos fazem ponderar que o Memorial Padre Cícero é em sua essência a forma mais direta da afetividade em sua tipologia "emoção", pois está assentado em tempo curto, patrimônio propositadamente posto para se viver uma afetividade efêmera, controlada e dependente da instituição. Por isso, tem-se a necessidade de fazer fila, do sujeito se identificar para se tornar numerável em estatísticas, não é aconselhável reverenciar pela genuflexão, não é permitido tocar, sentir os objetos, ou melhor, captar sua "potência sacral ou ritual". Neste sentido, os visitantes do Memorial não apreendem essa potência espiritual existente. Enfim, não é possível vivenciar o patrimônio, mesmo porque padre Cícero ali só faz parte da memória histórica, petrificada no passado e transposta para o presente. É onde se organiza e se controla a crença, o imaginário, o simbolismo, contribuindo para uma economia dos bens simbólicos (BOURDIEU, 2004), aqui especificamente para o turismo convencional.

Largo do Socorro: um patrimônio de tombamento afetivo de duração longa

O Largo do Socorro faz parte de um complexo patrimonial (Figura 2) religioso/mortuário/romeiro/visitacional/educacional/turístico e museal assentado na crença popular; lugar onde se encontram a sepultura e monumentos comemorativos devocionais a padre Cícero Romão Batista e de outros mártires da religiosidade do lugar a ele ligados. O afetivo em sua tipologia sentimento, dessa forma, será essencial para a discussão sobre patrimônio e tombamento afetivo no contexto de nossa reflexão. 
Figura 2. Aspectos da arquitetura da Igreja do Socorro e componentes de seu entorno. Foto: Autor, 2016.

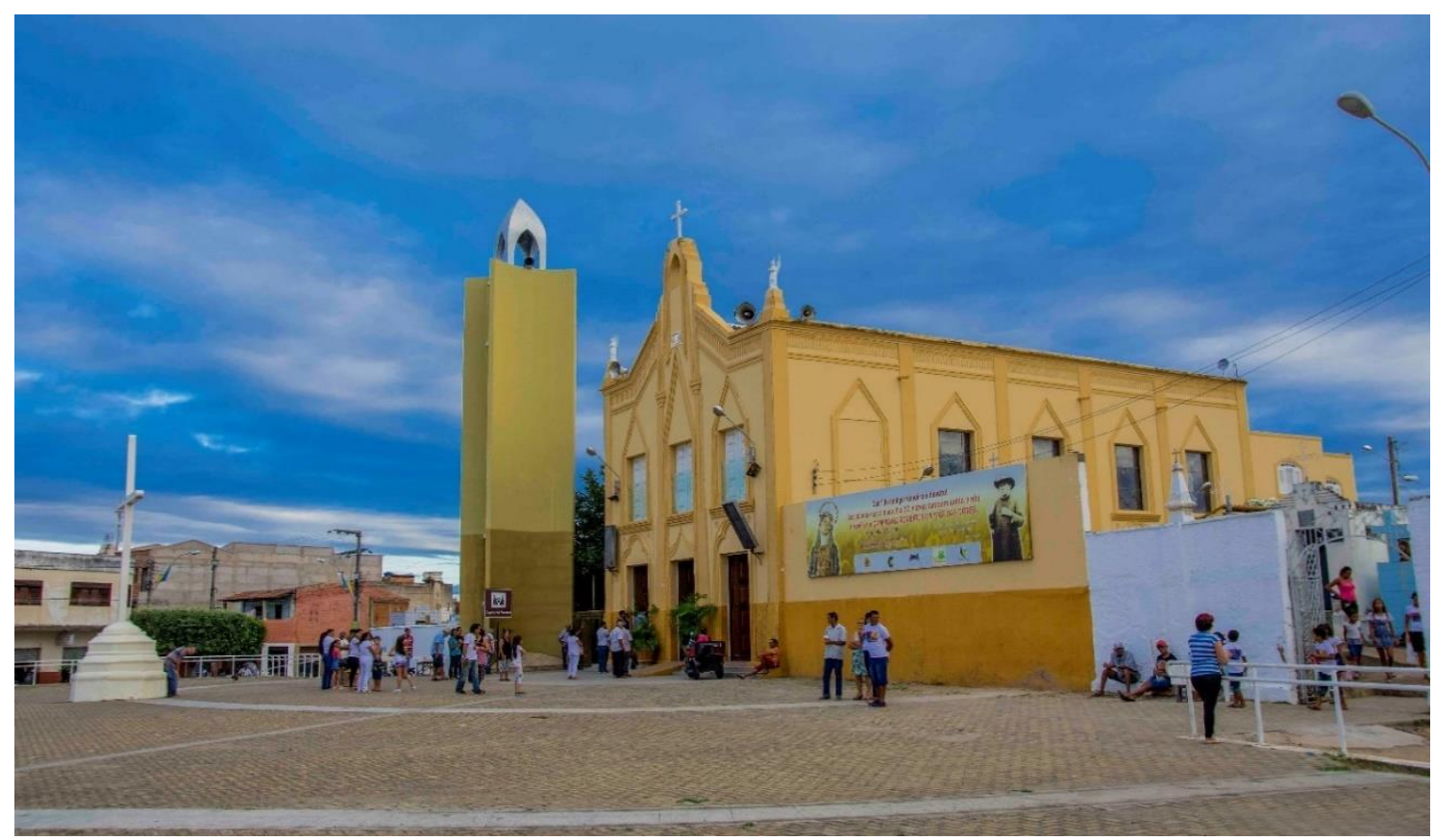

O Largo do Socorro está localizado no centro de Juazeiro do Norte, próximo ao marco zero da cidade. Apresenta-se ladeado pelas ruas Monsenhor Joviniano Barreto, Rua Santa Cecília, Rua da Conceição, Rua Leandro Bezerra e Rua Santa Rosa.

No contexto da evolução urbana de Juazeiro do Norte, o Lago do Socorro não possui um traçado regular, pois cresceu e formou-se aleatoriamente. Trata-se historicamente da falta de controle urbano que, pouco a pouco, se desenhou graças aos arruamentos desordenados ocorridos durante o processo de crescimento da cidade. Atualmente ele segue o traçado das ruas e dos edifícios que o rodeiam. É um espaço amplamente aberto com exceção do cemitério público municipal, que faz parte do complexo, mas está cercado por muros e cujas entradas principais localizam-se ao lado da Igreja do Socorro, onde está sepultado o corpo de padre Cícero. A igreja fica dentro da área do cemitério, também de valor simbólico afetivo inestimável para os romeiros.

As reflexões a respeito do Largo do Socorro requerem um pequeno esclarecimento e introdução. Ao tratarmos desse ajuntamento patrimonial cujo conjunto é constituído, na sua maioria, de patrimônios religiosos, isso não quer dizer que a afetividade que Ihes envolve seja uma afetividade irracional, mesmo porque a afetividade é uma condição orgânica e não uma condição escatológica, partindo de uma fé, por exemplo. Utilizaremos uma reflexão de Dominique Poulot (2009, p. 12) como ponte e caminho para sairmos do "lugar de patrimonialização" e chegarmos ao "lugar de patrimônio", o de tombamento afetivo de tempo longo. 
O patrimônio não é passado, já que sua finalidade consiste em certificar a identidade e em afirmar valores, além da celebração de sentimentos, se necessário, contra a verdade histórica. Nesse aspecto é que a história aparece, com tamanha frequência, "morta" no sentido corrente. Mas, ao contrário, o patrimônio é "vivo", graças às profissões de fé e aos usos comemorativos [e de vida] que o acompanham.

A citação acima pode nos conduzir em trajetória considerada adversa, pois o "lugar de patrimonialização" difere-se sensivelmente do "lugar de patrimônio". Este último construído de forma natural, originário da vitalidade da cultura local, estabelecendo o lugar-comum dessa afirmação cultural, onde a ética é pré-condição essencial para o seu reconhecimento.

Assim, o "lugar de patrimônio" remete ao conceito de patrimônio popular ou social, aquele constituído nos laços estabelecidos no seio e na lógica da coletividade, em sua diversidade. Para Rautenberg (2007), quando se trata de patrimônio social, as transmissões das lembranças e heranças culturais estão sedimentadas no lugar e no presente e não no passado histórico. Dessa forma, as memórias vivas transformam os lugares em patrimoniais, ou, lugares de patrimônio.

O “lugar de patrimônio" não passa por processos de revitalização ou reabilitação, sua constituição inicial é uma marcação social por excelência, de veia afetiva abalizada tanto pela emoção quanto principalmente pelo sentimento; é a assinatura social no espaço em movimento constante, um círculo virtuoso cuja renovação acontece cotidianamente, no tempo longo. Neste sentido, o Largo do Socorro é oposto ao Memorial Padre Cícero, mesmo esse estando localizado em seu interior.

Às práticas e às apropriações estão associados os discursos, pois o patrimônio participa de um princípio narrativo, pois não há patrimônio sem aqueles que o narram e estão em interação. Cada componente patrimonial do Largo do Socorro é uma narrativa expressa pelo popular. O patrimônio conta os mitos de origem, as epopeias fundadoras, os mais importantes momentos históricos de um grupo e, por conseguinte, de um território, de um lugar onde se estabelecem as interações sociais. O patrimônio é um projeto coletivo para o futuro (DI MÉO, 2007).

O Largo do Socorro é patrimônio social, o patrimônio comemorado e de sentido primeiramente humano, vivido e de valor afetivo abundante (DARDEL, 2011), cuja afetividade em torno de sua paisagem é uma das principais necessidades elementares da existência individual ou coletiva, a emoção primeva da qual se refere Besse (2011), analisando a obra de Dardel. Paisagem impregnada dos cinco sentidos humanos dos que praticam o lugar sob os auspícios da emoção e dos sentimentos em "[...] uma espécie de geografia afetiva que repercute nos poderes dos lugares possuidores de impacto sobre a imaginação" (BESSE, 2010a, p. 14), é uma paisagem sensorial, ou mesmo, como denomina, "poli-sensorial", ligado à questão do corpo vivo, ou corpo sensível, oposto do corpo físico, ponto atribuído a propriedades teóricas diversas elaboradas pela 
ciência e cuja realidade é inexistente a exemplo das formas de grandezas. Assim, complementa o filósofo, a paisagem poli-sensorial é o centro dos afetos, o centro e o receptáculo das espacialidades afetivas. O Largo do Socorro, nesta perspectiva, adquire uma carga ontológica e fenomenológica perfeitamente decisiva: não é para o nosso próprio corpo que habitamos o mundo (BESSE, 2010a).

Levando em consideração estas assertivas, o habitar e a paisagem do Largo do Socorro seriam em sua essência um só corpo, construídos e reconstruídos, necessariamente, na ordem fenomênica, na ordem do vivido, sobre o plano da sensibilidade afetiva.

A geografia do sentimento, da sensibilidade e afetiva é mais uma geografia vernacular, do contato com o mundo e o espaço cotidiano e da familiaridade fundada sobre o uso, uma geografia vivida e pensada e uma maneira de ser-no-mundo. Daí Besse (2010a) chamar atenção que esta geografia não deve ser levada a ser pensada como uma geografia "interior", ou geografia da "alma". Não é uma geografia subjetiva que exclui o mundo e o espaço, é uma geografia que está fora, no exterior, está exposta.

O Largo do Socorro é o lugar dos encontros e das práticas comunitárias dos atores coletivos permanentes (SANCHIS, 1983), praticadas sem obedecer a controles rígidos (Figura 3). Nele são exercidas a sociabilidade, a civilidade e a acessibilidade, características fundamentais de um espaço público. Daí sua condição de lugar excepcional e diferenciado em relação a outros lugares na cidade. É o lugar onde se instituem as linhas de força (THRIFT, 2004) criadas pelas emoções, pelos sentimentos, pelas memórias vivas e em agitação. São os grupos ou indivíduos isolados quem ditam seus itinerários, sem negar, é claro, os conflitos internos existentes entre eles.

Figura 3. Largo do Socorro em tempo de romaria no ano de 2010. Foto: Autor, 2010.

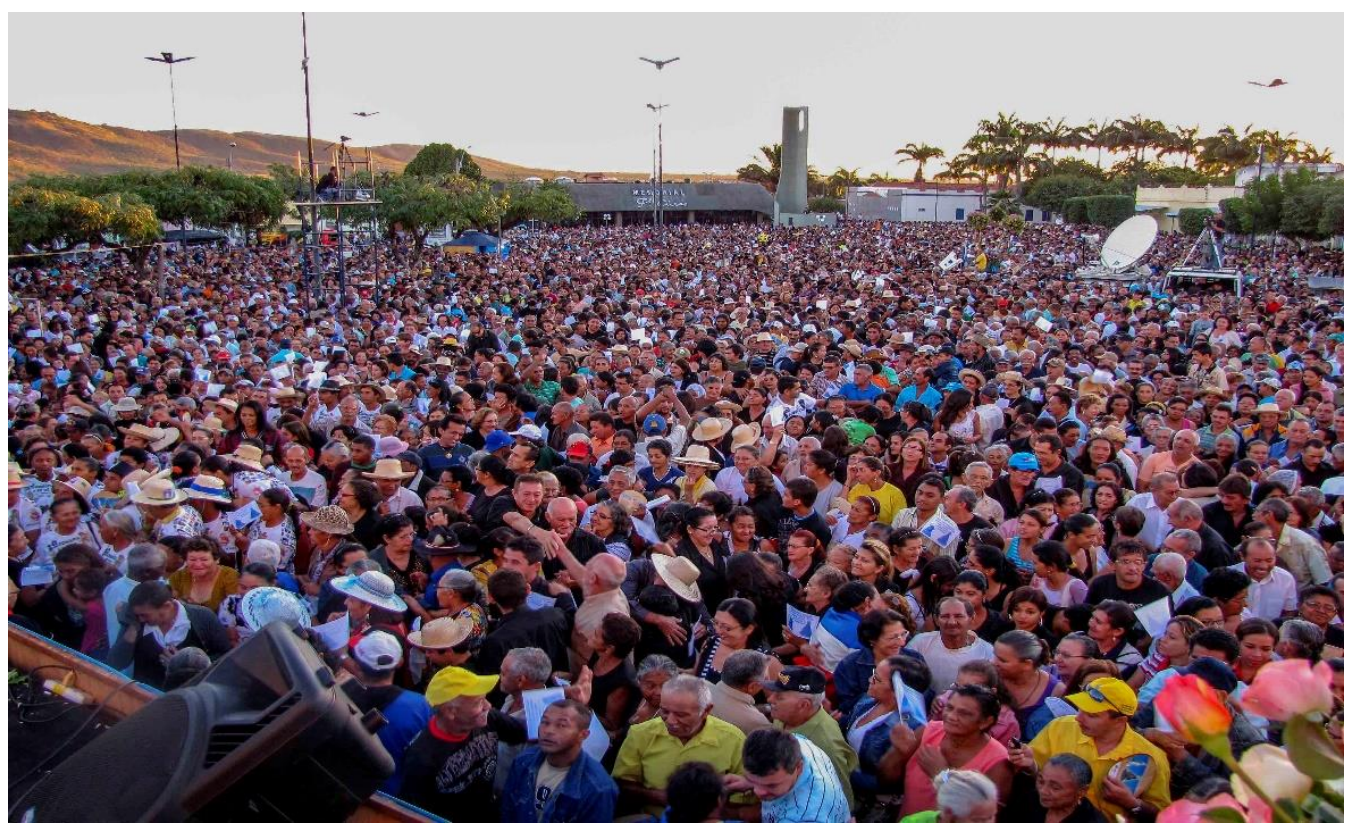


Não é uma instituição que os fazem reconhecer o que deve ser seus patrimônios, são os próprios sujeitos e os objetos culturais em uma troca simbólica. Essa troca simbólica entre o sujeito e o símbolo (objeto) pode ser levada ao que Berque (2007) teoriza sobre "autenticidade". Em outras palavras, a autenticidade não é a fria identidade de um objeto e nem sua exatidão científica, abstrata, neutra, catalogada. A autenticidade se caracteriza pela soberania do sujeito agindo em relação direta com o objeto "agido", é ainda o esforço de construção do próprio sujeito e de sua relação com as coisas que o envolve, a autenticidade se desenvolve em seu próprio espaço-tempo.

O Largo do Socorro permite, então, a transmissão de sentimentos que se acumularam, se acumulam e findam em sua sedimentação. É o lugar da memória social coletiva dos moradores e visitantes encenada nos relatos produzidos a partir deles próprios ou transmitidos para eles do e para o lugar. São também lugares do patrimônio de vida e do vivido porque estão vinculados às experiências pessoais individuais e coletivas. O lugar sem detentor único, cuja identificação, proteção e valorização partem do corpo social, são alimentadas através das simbologias e dos imaginários. Como patrimônios tradicionais, eles asseguram a reprodução da ordem simbólica lugar, considerando que as relações entre o os objetos, as imagens e os relatos encontram harmonia e finalidade na manutenção e perenidade dos símbolos (JEUDY, 1990). O Largo do Socorro é lugar dos encontros e das práticas religiosas, lugar excepcional e diferenciado em relação a outros lugares na cidade.

Para Di Méo (1996; 2007), as relações espaciais, além de corresponderem aos substratos econômicos, políticos e jurídicos, são afetivas ou mesmo puramente imaginárias, de contorno material e simbólico.

O geógrafo divide o espaço social primeiramente como espaço de vida, ou melhor, como espaço do cotidiano das pessoas, de suas práticas como a rotina das relações interpessoais gerais dos lazeres, do labor ou da vida associativa referente às necessidades pessoais e familiares. Em seguida, vem o espaço vivido, o que ele chama de espaço de sonho. A característica do espaço vivido diferencia-se do espaço de vida por estar relacionado a valores culturais e psicológicos mais abstratos. O espaço vivido é o espaço de "[...] projeções subjetivas, oníricas e imaginárias, provenientes das psiques individuais e dirigidas sobre os espaços reais" (DI MEO, 2007, p. 148). Assim, o espaço vivido é uma apropriação do espaço a partir da experiência fenomenológica dos sujeitos em relação a si próprios e ao grupo social e exprime a relação existencial dos sujeitos na sociedade e no lugar.

O lugar de patrimônio "Largo do Socorro", desse modo, é espaço social tanto da vida dado às relações concretas estabelecidas ao seu redor e interior quanto espaço vivido, porquanto é espaço fenomenologicamente existencial, dos sujeitos imersos em si, em sua transcendência, mas sem perder a referência da matéria em volta e a qual os abarca e estão conectados, são seus referencias no espaço. 
O lugar "Largo do Socorro" enquanto lugar da vida e do vivido está situado na convergência de três polos inerentes à fenomenologia: os polos da afetividade, da historicidade e do social (SERFATY-GARZON, 1985), os quais estão intimamente ligados à "geograficidade" de Dardel (2011) e assinalados nos seguintes termos:

\begin{abstract}
[...] por afetividade são designados os investimentos do sujeito, por exemplo, na apropriação "positiva" [...] ou "negativa" [...] do espaço [...]. A noção de historicidade faz referência ao componente temporal da relação ao mundo do corpo-sujeito através das percepções pessoais, as lembranças, as antecipações ou, para empregar uma terminologia husserliana, as retenções e as proteções que constituem a intencionalidade. Por social são entendidas as comunicações, as análises da linguagem e do trabalho, da ação sobre o mundo. A experiência do espaço depende daquilo que o sujeito pode "nele fazer", da natureza das ações que pode exercer sobre ele. Do mesmo modo, os lugares são marcados pelas palavras que os designam a acessibilidade, os modos de uso, as qualidades positivas ou negativas em função do contexto cultural onde a pessoa se encontra (SERFATY-GARZON, 1985, p.65) [grifos da autora].
\end{abstract}

Castro (1997) assevera sobre a importância do valor explicativo do registro simbólico sobre o espaço apesar da racionalidade moderna ter conquistado os espaços objetivos, o que faz do símbolo parte integrante dos estudos geográficos. O simbólico, neste sentido, é base das representações que orientam as ações dos homens sobre o espaço, mesmo porque o espaço é concomitantemente continente e conteúdo de signos e símbolos. Problematizar o espaço é considerar seus paradoxos e, assim, possibilitar "[...] responder à questão de como se forjam desigualdades a partir da articulação do espaço da função política com outras dimensões do espaço da sociedade" (CASTRO, 1997, p. 162).

Considerando todas essas questões, estamos em pleno acordo de que a relação do sujeito no mundo não somente ocorre na relação sujeito-objeto concreto materializado no espaço, ou, na relação de um para o outro, na mediação, ela é, sobretudo, intersubjetiva. Observamos que a geografia fenomenológica existencial nos ajuda a ir mais intensamente à questão da essência do sujeito, do ser-no-mundo, pois ela nos parece somar e enriquecer a Geografia das relações discutida pelos geógrafos. Por isso, acreditando e tomando como curso de nosso pensamento a geografia fenomenológica, a partir de Hoyaux (2008), consideramos que:

Se o homem se coloca ele próprio no espaço, é porque ele tem a capacidade de materializar neste espaço a ideia, principalmente por meio de seu corpo, seja pela projeção física (corporalidade) ou pela projeção mental (corporeidade) que ele opera através do corpo junto ao espaço, de uma porção dele ou através dos objetos, dos indivíduos que aí se encontram. Espaço não forçosamente presente, mas também presentificado, imaginado, fantasmagorizado [...], artefatualizado. [...] o indivíduo não se coloca somente em um espaço objetivo, até mesmo, não se desloca em um espaço representado, em uma espécie de paisagem, um horizonte que o desafiaria, e que o colocaria à distância para melhor o apreender, e a ele se dirigir. Não, a ideia é que sua matéria - corpo e alma - habita o espaço por sua copresença. Esta copresença gera, desse modo, o mundo realmente apreendido pelo indivíduo e ao qual ele está de acordo em seus atos e pensamentos. Isto quer dizer que ele não reage às instâncias materiais "objetivas" às quais seria confrontado, mas que ele se conforma às construções materializadas, aos artefatos mentais [...]. O indivíduo não vive em um campo de limitações, mas num campo de possibilidades que ofereceria estas instâncias, que ele as materializaria, e no seio das quais ele selecionaria, assim, os elementos, compondo seu campo de expressão e de ação (HOYAUX, 2008, $\mathrm{s} / \mathrm{p})$ [grifos nossos]. 
Corporalidade e corporeidade são distinguidas pelo autor levando em conta a seguinte reflexão: a corporalidade está relacionada ao "espaço-território", ao concreto, à base sólida, ou seja, é a ação que se desenvolve no contexto em que o corpo físico se encontra. A corporeidade refere-se ao que ele denomina "espaço-rede", ou melhor, ao espaço não físico, não sólido, é a ação que acontece em um contexto no qual o corpo físico não se encontra, por exemplo, o ato artístico, o movimento, o imaginário, as simbologias etc., mas que são entidades reais e substanciais (HOYAUX, 2008).

Reforçando o pensamento do referido geógrafo, este aspecto da fenomenologia conduz a realidade espacial não só concebida a partir do seu estrato material, o que ele chama de "matéria na presença" (espaçoterritório), porém, considera que a materialidade do espaço também se constrói a partir do conjunto de elementos "não presentes no espaço objetivo" (espaço-rede). Por isso, acreditamos que a espacialidade dos sujeitos envolvidos na constante reelaboração e manutenção do Largo do Socorro ocorrem levando não somente em conta o espaço concreto e seu patrimônio objetivado, isto é, da relação direta sujeito-objeto, mas ainda do estatuto e dos papéis que se desenvolvem no, com e através deste espaço (HOYAUX, 2008).

Nisto, a força e a intensa dinâmica simbólica do lugar de patrimônio Largo do Socorro fazem com que moradores e visitantes o transcendam. Reforçam-se estas considerações, pois o imaterial não afronta oposicionalmente a racionalidade do espaço material, o potencializa. Desse momento em diante os sujeitos atuantes neste lugar vivem uma realidade imaginal, até porque o homem não escapa do imaginário contido em seu lugar de eleição, lugar de luta para seu reconhecimento (DORFIAC, 2000).

Dardel (2011) consegue sintetizar estas considerações mostrando o lugar como produto das relações e das trocas interpessoais, onde sujeitos tomam consciência do mesmo apropriando-o através de uma situação geográfica particular, geografia capaz de extravasar as mais variadas experiências e, essas experiências geográficas "[...] sem sair do concreto, empresta seus símbolos aos movimentos interiores do homem" (DARDEL, 2011, p. 14) que no lugar habita ou, dependendo do contexto em que se encontra este lugar, o visita.

Compreende-se, dessa forma, que não há vida no material sem seu invólucro imaginário. Augustin Berque (1997, p. 291) vem explorando a fenomenologia na geografia e a importância do habitar neste contexto. Para ele, "[...] o habitar humano sobre a Terra não é somente de ordem física ou ecológica: ele é também fundamentalmente, e mais especificamente, de ordem simbólica; ou seja, ele alia concretamente o físico e o imaginário. Ele é ecossimbólico" [grifo do autor]. Considera este entrelaçamento, esta aliança, uma realidade poética, ou como diz: é uma realização do ecúmeno funcionando como um "poema do mundo".

A corporeidade atuante no "espaço-rede", no sentido geográfico fenomenológico existencial do termo, encontra seu homônimo na concepção psicológica de mesma linha. Trata-se de uma relação estreita em termos conceituais. A corporeidade psicológica fenomenológica pode ser então, aquela a qual “[...] estende- 
se muito além de nossas sensações do momento, pois não nos encontramos, apenas, fisicamente localizados num determinado lugar, mas expandindo-nos em nosso existir no mundo, um mundo que é constituído não apenas de sensações, mas de significações [...]" (FORGHIERI, 1997, p. 30). É na realidade dessa capacidade natural do homem de expansão de seu corpo como presença em diferentes esferas que a citação se quer fazer entender, a capacidade humana de transcender por meio da consciência das situações cotidianas vivenciadas, ou melhor, das diferentes possibilidades oferecidas pelo mundo.

É assim que o Largo do Socorro, diferentemente do Memorial Padre Cícero, é lugar o qual ensina a seguir a "pedagogia do vivo", suscetível de ser atualizável, pois os monumentos ali localizados estão assujeitados e sob a salvaguarda da memória coletiva viva e em efervescência dos que para ali vão para projetar e enriquecer seus imaginários simbólicos, ressignificando-os incessantemente. Assim ocorrendo, o Largo do Socorro se transforma em um gigantesco memorial dos afetos do tempo longo a céu aberto, para mostrar que os monumentos existentes no lugar significam e demonstram que a representação da morte de padre Cícero não foi inútil.

Dessa forma, o conjunto paisagístico patrimonial deste memorial social faz com que cada sujeito tornese "[...] intérprete à sua maneira, do legado que ele reivindica [...]" (POULOT, 2009, p. 238) e, isto ocorrendo, protege-se e interioriza-se a riqueza simbólica e cultural de que é depositária. São símbolos religiosos com propriedades comuns, pois "[...] representam, concretizam, evocam um conjunto de ideias ou sentimentos, ou seja, uma fé [...]" (POULOT, 2009, p. 101-102). Sua imponência foge significativamente aos cânones regulares da racionalidade instrumentalizada e institucionalizada do Memorial, porquanto as memórias coletivas do lugar não seguem a sua gestão político administrativa (JEUDY, 2005) promotora de uma “melancolia cívica" patrimonial (POULOT, 2009).

Esta pedagogia do vivo já vem dada, não é fabricada, vem adquirida, não é necessário chegar, ver, e só depois aprender e repassar, porém, apesar de ser adquirida, não nos enganemos: se aprende ininterruptamente, há uma renovação constante de aprendizagem. Por isso a "pedagogia do vivo" é “[...] motivadora de uma educação patrimonial diferenciada, por que especial [...]" (CAVALCANTE, 2011, p. 59) [grifo do autor], em relação ao Memorial detentor de uma pedagogia de natureza fortemente lógica.

Damery (2008) já nos quis demonstrar que somente o ambiente afetivo marca a alma do homem e do lugar na construção do espaço público. O lugar de patrimônio Largo do Socorro como espaço público desperta emoções e sentimentos onde se encontra o afeto. Dessa forma ele segue em tombamento perene dado à constância afetiva de seus praticantes para com um espaço público do quotidiano transformado em espaço sagrado, sacralizado. 
Rautenberg (2003) chama atenção de que existe uma patrimonialidade mais ou menos transitória e esta só tem significado através das práticas sociais que a produzem como paisagens reproduzidas pela sociedade. O nosso caso está relacionado à paisagem já construída e fixa apropriada afetivamente, mas isso não quer dizer que não possa ser modificada ou mesmo desaparecer o afeto a ela dedicado.

O lugar de patrimônio é utilitário e democrático, o contato físico é incondicional e para todos. O toque funciona ao mesmo tempo, como canal comunicativo e condutor de energias, é o experimentar da "potência dos objetos" relíquias (Figura 4). Muitos dos objetos que estão a ele ligados podem se transformar nessas relíquias acessíveis, muitas passíveis de serem levadas como reais troféus sagrados. No lugar do patrimônio Largo do Socorro é comum o transcender do sujeito individual ou coletivo e nisso, a interação comunicacional em todas as suas formas é fundamental.

Figura 4. Nicho onde se encontra a imagem de Padre Cícero. Foto: Autor, 2016.

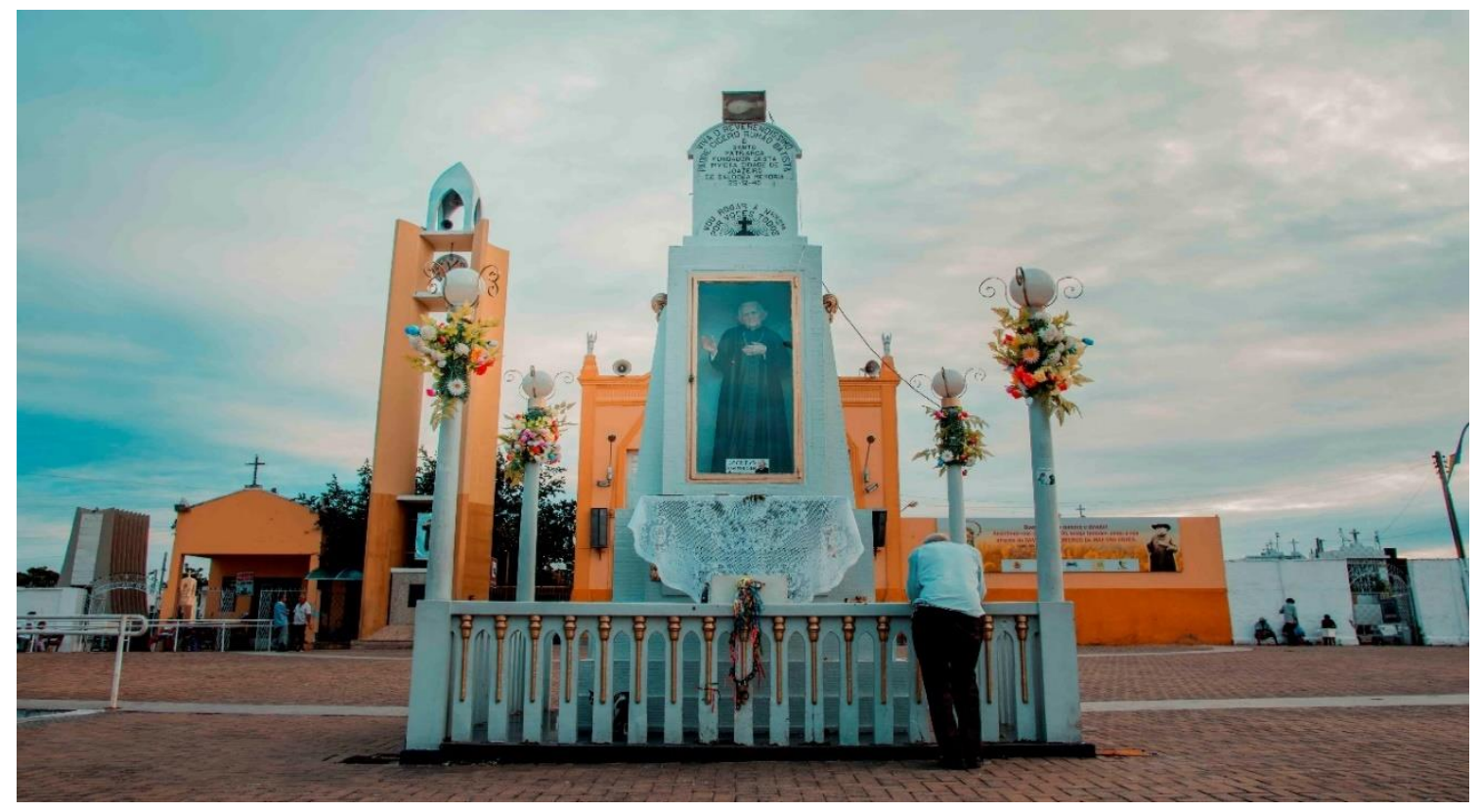

No sentido de formular uma conceituação que dialogue com o espaço público de Damery (2008) e Berdoulay, Castro e Gomes (2001), com o objetivo de reforçar a condição do Largo do Socorro inserido neste contexto, ou seja, o espaço público de simbolismo denso e da cotidianidade afetiva na dimensão do uso dos habitantes comuns, trazemos a visão de Besse (2006; 2010a; 2010b) cuja reflexão remete este espaço inserido nas experiências política e social modernas. Este filósofo abre o entendimento de espaço público na forma de uma linguagem ordinária, espaço este de compreensão e participação de todos, o que chama de espaço público do "ponto de vista do habitante não especialista". Sua maneira de conceituar o espaço público de forma mais geral é, antes de tudo, a de entendê-lo como aquele 
[...] espaço coletivo ou plural da experiência de si, dos outros, e do ambiente em geral; este espaço não é econômico ou funcional, mas político, mesmo moral e cultural [...]; este espaço político não é aquele do Estado (ou da administração); é um espaço não identitário, não fusional, e que, doravante, não é completamente administrado ou controlado, um espaço informal, em outros termos (BESSE, 2006, p. 4).

Pode-se considerar o lugar de patrimônio Largo do Socorro embebido destas prerrogativas por nele serem encontradas formas sociais conduzidas pela linguagem ordinária exposta por Besse (2006). A linguagem ordinária, comum ou mesmo vernacular da qual o autor se refere, não se trata de uma linguagem desprovida de valor. Muito pelo contrário, o valor desta linguagem está justamente na forma de compartilhamento universal relativo ao próprio lugar cujos indivíduos dele tiram proveito deixando que seus semelhantes também se apropriem ou participem política, moral ou culturalmente. Podemos exemplificar a linguagem ordinária com o nicho de padre Cícero que funciona ao mesmo tempo como canal comunicativo e condutor de energias, é o experimentar da "potência dos objetos" relíquias.

No Largo do Socorro, espaço do usuário não especialista, ocorre apropriação com construção de lugar patrimonial social por sua característica afetiva dinâmica. Neste espaço acontece mais do que uma simples preservação ou conservação. No Memorial, envolto à especialização, desenvolve-se patrimonialização sem apropriação, quando o patrimônio é classificado como mero objeto de coleção e transmite afetividade centralizada somente no tempo curto. $O$ tombamento afetivo no nosso caso particular de patrimônio assume a realidade de que

[...] as emoções [e sentimentos] pertencem ao domínio do cotidiano e sua análise permite refletir na escala individual e social para estudar como normas e representações sociais ou culturais influenciam sobre a prática e a experiência emocional do lugar, como as experiências afetivas [sentimentais] e emocionais [...] participam da construção de uma relação complexa do mundo e do espaço que se transforma, se amplia ou se contrai segundo a vontade das emoções [e dos sentimentos] [...] (MAULION, 2009, p. 40).

Quando se faz a separação do afeto em seus tipos, emoções (curto) e sentimentos (longo), isso não quer dizer que eles estão isolados um do outro e as emoções não sejam importantes, principalmente para a Geografia. Emoções e sentimentos fazem parte de um mesmo processo de constituição cognitiva e condição da essência humana, mesmo porque no contexto do espaço social as emoções pertencem ao domínio do cotidiano, como afirma acima Maulion (2009). Ao estudar a geografia das emoções, ela percebe que a partir dela é possível se estabelecer uma transição entre o ideal, o material e a sociedade, levando à construção de uma geografia da "médiance" ou "relacional".

As emoções (como a afetividade) podem ser trabalhadas tanto nas questões ambientais quanto nas culturais e patrimoniais em geografia, apesar dos poucos estímulos a este tema. Damery (2008) diz que a emoção, compreendida na experiência do público, é condutora de função original quando se trata da problemática da instituição da cultura e das modalidades da experiência política sobre a questão. Para ambos 
os casos, relativos ao patrimônio ambiental e ao patrimônio cultural, a emoção é definida pelo evento do qual ela advém, o que ela chama de razões da emoção patrimonial.

\section{CONSIDERAÇÕES FINAIS}

Uma geografia implicada na busca de relações mais significativas entre a condição humana e seu meio socioambiental proporciona outra leitura científica sobre o papel da afetividade. Historicamente, a geografia vem tentando compreender as diversas formas como o homem habita a Terra inteirando-se sobre a percepção do ambiente utilizando-o e modificando-o de forma utilitária e funcionalista.

Os esforços epistemológicos de superação para uma nova fronteira de entendimento do espaço apontam que as formas utilitaristas e funcionalistas não dão conta da complexa rede dos grupos sociais os quais desenvolvem suas atividades no mundo. O pioneirismo de Eric Dardel, Augustin Berque e mais recentemente André-Frédéric Hoyaux, entre outros, nos mostram que um dos principais problemas referentes à humanidade é a questão que envolve a sua existência. As perguntas clássicas de cunho filosófico: Quem somos nós, De onde viemos, Para onde vamos, Quais nossos propósitos na Terra, entre tantas outras, podemser reconduzidas em termos geográficos; mesmo reconhecendo que a abordagem fenomenológica de seu estudo não ultrapassa os condicionantes contextuais do universo ideológico da sociedade em questão.

O Largo do Socorro é um patrimônio social, ele ocupa e marca um espaço, sendo uma elaboração sobremaneira do e sobre o homem religioso padre Cícero e seus seguidores. É uma narrativa que conduz ao lugar de morada cujo uso e apropriação leva a uma determinada forma de afetividade, negativa ou positiva, como também a uma forma ideológica de valorização, de apropriação e de transformação desse espaço.

Tal patrimônio é necessariamente geográfico, pois constrói e alimenta territórios, concretos, imaginais ou imaginários. Patrimônio que em sua condição social requer antecipadamente um tombamento afetivo, porquanto o espaço insiste em transmitir a essência do espírito humano. As religiões em geral, e a religião popular, no nosso caso, procuram estruturar as relações existentes entre o concreto e o abstrato. $O$ patrimônio Largo do Socorro e seu conjunto patrimonial associado, testemunha a força social dos imaginários e das simbologias produzidas no curso da vida dos moradores da cidade e de seus visitantes ilustres, os romeiros.

Patrimônio social construído no cotidiano - sobretudo, nos discursos, nos relatos, nos causos, nas músicas, histórias, canções e ladainhas populares - o Largo do Socorro torna-se um mecanismo remodelador da patrimonialidade incessante. Tanto na vitalidade do espaço geográfico que identifica a cidade/metrópole de Juazeiro do Norte, quanto na capacidade de atualizar a memória de padre Cícero em uma complexa trama de símbolos e meios de tornar inseparável fé e lugar da fé. 


\section{REFERÊNCIAS}

BERDOULAY, Vincent; CASTRO, Iná E.; GOMES, Paulo C. da C. L'espace public entre mythe, imaginaire et culture. Cahiers de Géographie du Québec, vol. 45, $n^{\circ} 126$, 2001, p. 413-428.

BERQUE, Augustin. Basho, Chôra, Tjukurrpa, ou le poème du monde. Espace géographique, Tome 26 n4, p. 289-295, 1997.

. Lieu et authenticité. Cahiers de géographie du Québec, vol. 51, n 142, p. 49-66, 2007.

BESSE, Jean-Marc. L"espace public : espace politique et paysage familier. Rencontres de l'espace public, Lille Métropole Communauté Urbaine, Lille, p. 1-18, 14 décembre 2006.

. Le paysage, espace sensible, espace public. META: Research in Hermeneutics, Phenomenology, and Practical Philosophy, Vol. II, no. 2, p. 259-286, 2010a.

. L'espace du paysage: considérations théoriques. International Seminar Theory and Landscape: Interdisciplinary Perspectives. Barcelona, p. 7-24, 25th and 26th of February $2010 \mathrm{~b}$.

. Geografia e existência a partir da obra de Eric Dardel. In: DARDEL, Eric. O Homem e a Terra: natureza da realidade geográfica. Tradução de Werther Holzer. São Paulo: Perspectiva, 2011. p. 110-139.

BOURDIEU, Pierre. A produção da crença: contribuição para uma economia dos bens simbólicos. São Paulo: Zouk, 2004.

CASTRO, Iná E. de. Imaginário político e território: natureza, regionalismo e representação. In: CASTRO. Iná E. de; GOMES, Paulo C. da C.; CORRÊA, Roberto L. (orgs.). Explorações Geográficas. Rio de Janeiro: Bertrand Brasil, 1997. p. 155-196.

CAVALCANTE, Tiago V. A casa da Mãe de Deus comporta o (outro) mundo: dinâmicas geográficas no Santuário de Fátima em Fortaleza - CE. 2011. 158f. Dissertação (Mestrado) Programa de Pós-Graduação em Geografia da Universidade Federal do Ceará. Fortaleza, 2011.

CLAVAL, Paul. “A volta do cultural” na Geografia. Mercator - Revista de Geografia da UFC, ano 01, número 01, p. 19-28, 2002.

DAMÁSIO, Antonio. A base biológica das emoções. Revista Viver Mente \& Cérebro Scientific American, Ano XIII №143 - Dezembro 2004, s.p.

DAMERY, Claire. Espace public, patrimoine et milieu affectif: exemples du Marais d'Orx et du Domaine d'Abbadia. 2008. 501f. Thèse (doctorat) de l'Université de Pau et des Pays de l'Adour. Institut de Recherche sur les Societes et l'Amenagement. École Doctorale Sciences Sociales et Humanites. Societé, Environnement et Territoire. France, 2008.

DARDEL, Eric. O Homem e a Terra: natureza da realidade geográfica. Tradução de Werther Holzer. São Paulo: Perspectiva, 2011.

DI MÉO, Guy. Les territoires du quotidian. Paris: L’Harmattan, 1996.

. Processus de patrimonialisation et construction des territoires. In: ADES - Aménagement, Développement, Environnement, Santé et Societés. Univesité de Bordeaux Segalen, 2007. p. 1-19.

DORFIAC, Claude. Millénarisme et utopie. Quaderni. N. 42, p. 17-23, Automne, 2000.

DURANT, Gilbert. L’a logique du mythe. Religiologiques, n. 10, automne 1994. Disponível em:

<http://www.religiologiques.uqam.ca/no10/duran.pdf>. Acesso em: 1 junh. 2012. pp. 27-47.

FORGHIERI, Yolanda C. Psicologia fenomenológica: fundamentos, métodos e pesquisa. São Paulo: Pioneira, 1997.

HOLANDA, Aurélio B. de. Novo Dicionário da Língua Portuguesa. Rio de Janeiro: Editores J. M. M. M, 1986.

HOYAUX, André-Frédéric. Habiter la ville et la montagne: essai de géographie phénoménologique sur les relations des habitants au lieu, à l'espace et au territoire. (Exemple de Grenoble et Chambéry). 2000. 736f. Thèse (doctorat) Université Grenoble 1 - Joseph Fourier UFR de Géographie, 2000. 
. Matérialiser son monde à travers le corps: reflexions phénomenologiques sur le passage du perceptuel à l"artificiel. Colloque Turbulences dans la Perception, Pessac, 13 et 14 Mars 2008, Pessac, France, 2008. s/p.

JEUDY, Henri-Pierre. Memórias do social. Tradução de Márcia Cavalcanti. Rio de Janeiro: Forense Universitária, 1990.

Espelhos da cidade. Tradução de Rejane Janowitzer. Rio de Janeiro: Casa da Palavra, 2005.

JUAZEIRO do Norte. Plano de Ação Turística de Juazeiro do Norte - PAT. Juazeiro, 2000.

MAULION, Helen. Cheminements et recits atlantiques: pour une geographie paysagere sensible en movement. 2009. 301f. Thèse (doctorat) de l'Universite de Nantes. Institut de Geographie et d'Amenagement Regional (IGARUN). Nantes/France, 2009.

MONNET, Jérôme. Interpréter et aménager : eléments d'une géographie de la relation au monde. Dossier de canidacture à I'habilitation à diriger les recherches. Paris, 1999.

. La interpretación del mundo, de la representación a la acción: una mirada desde la geografía francesa. In: CAPRON, Guénola; MONTES, Carmen I.; LEVI, Silvana, CARBÓ, Eulalia, R.; THIÉBAUT, Virginie. (dir.). La Geografía contemporánea y Elisée Reclus. Collection: Hors Collection, Mexico, 2011. p. 135-159.

OLIVEIRA, Christian D. M. de. Desafios contemporâneos das cidades-santuários no estado do Ceará (Brasil): políticas patrimoniais e diocesanas. Geosaberes - Revista de Estudos Educacionais da UFC, v. 1, n. 1, maio/2010. p. 37-51.

POULOT, Dominique. Um ecossistema do patrimônio. In: RODRIGUES, Cláudia S. et al. Um olhar contemporâneo sobre a preservação do patrimônio cultural material. Rio de Janeiro: Museu Histórico Nacional, 2008. p. 26-43.

Uma história do patrimônio no Ocidente, séculos XVIII-XXI: do monumento aos valores. Tradução de Guilherme João de Freitas Teixeira. São Paulo: Estação Liberdade, 2009.

RAUTENBERG, Michel. Comment s'inventent de nouveaux patrimoines: usages sociaux, pratiques institutionnelles et politiques publiques en Savoie. Culture \& Musées, n¹, p. 19-40, 2003.

Mémoires collectives, patrimoines et projet culturel dans le territoire urbain. Séminaire du programme interministériel: cultures, villes et dynamiques sociales. Écomusée du Creusot-Montceau, Château de la Verrerie, p. 11-13, Jeudi 22 et vendredi 23 Janvier 2004.

. Les "communautés" imaginées de l'immigration dans la construction patrimoniale. Les Cahiers de Framespa. N. 3 (2007) Patrimoine et immigration. Mis en ligne le 01 octobre 2007. p. 1-13.

SANCHIS, Pierre. Arraial: festa de um povo: as romarias portuguesas. Lisboa: Publicações Dom Quixote, 1983.

SERFATY-GARZON, Perla. Expérience et pratiques de la Maison. In: ALTMAN, Irwin et WERNER, Carol M. (dirs.). Home Environments, Human Behavior and Environment. Advances in Theory and Research. Salt Lake City, University of Utah: Plenum Press, New York, 1985. p. 65-86.

THRIFT, Nigel. Intensities of feeling: towards a spatial politics of affect. Geografiska Annaler. Series B, Human Geography, v. 86, n. 1. p. 57-78, 2004. 